\title{
Por uma unificação das tipologias de saberes docentes: em busca de consensos na formação de professores de ciências
}

Gabriela Agostini gabriela.agostini@unesp.br orcid.org/0000-0002-8909-4423 Universidade Estadual Paulista (UNESP), Bauru, São Paulo, Brasil

Luciana Massi

luciana.massi@unesp.br orcid.org/0000-0001-8761-3181 Universidade Estadual Paulista (UNESP), Araraquara, São Paulo, Brasil

\begin{abstract}
RESUMO
A temática saberes docentes é plural, complexa e cada vez mais frequente nas pesquisas sobre formação docente e ensino de Ciências. Há uma multiplicidade de tipologias, categorias e classificações decorrentes do acúmulo teórico e da expansão das pesquisas sobre o conhecimento dos professores desde os anos 1980. No entanto, ainda há poucas tentativas de unificar as diferentes tipologias. O objetivo desse artigo é discutir similaridades entre categorias do saber docente e apresentar, teórica e empiricamente, uma proposta de unificação das tipologias de saberes. Parte dos princípios de Tardif, Gauthier e Shulman para defender que: i) os termos saber e conhecimento são usados praticamente como sinônimos nas pesquisas sobre formação docente; ii) as definições para esses termos são semelhantes, pois decorrem de princípios equivalentes; iii) e as tipologias apresentadas por esses autores são diferentes, mas não excludentes. Este artigo propõe a unificação teórica de três tipologias: saberes disciplinares, saberes pedagógicos e saberes curriculares. Para ilustrar empiricamente a proposta de unificação, apresenta-se a análise de três professores de Química, novatos, formados em uma mesma instituição e com experiências profissionais distintas. Os dados foram constituídos a partir de entrevistas individuais, observações de aulas e notas de campo. Discute os saberes disciplinares, curriculares e pedagógicos observados nos três docentes, assim como, o desenvolvimento, a mobilização e as implicações desses saberes em suas práticas. Conclui defendendo que a unificação das tipologias tem como potencialidade ressaltar as relações entre as categorias do saber docente, operacionalizar o processo de análise, evidenciar elementos formativos da docência e apontar a urgência de investir em investigações menos descritivas sobre os saberes dos professores.
\end{abstract}

PALAVRAS-CHAVE: Conhecimento dos professores. Tipologia unificada. Tardif. Gauthier. Shulman. 


\section{INTRODUÇÃO}

Quase quatro décadas após o surgimento das pesquisas sobre os saberes docentes cabe o questionamento: quanto avançamos? Quais foram as contribuições dessas discussões e para onde ainda precisamos caminhar? Não pretendemos sintetizar essas pesquisas, pois existem sistematizações em Handbooks sobre o tema (MUNBY; RUSSEL; MARTIN, 2001). Há um consenso quanto ao papel fundamental e histórico dessas pesquisas para superar a ideia de uma profissão formada apenas por um conjunto de técnicas ou competências e definir o status profissional dos professores (GAUTHIER et al., 1998; NÓVOA, 1995; SHULMAN, 1986a). Por outro lado, o acúmulo teórico de trabalhos suscitou uma multiplicidade de tipologias, categorias e classificações.

Assim como Borges (2001, p. 72) entendemos que a multiplicidade teórica, metodológica e tipológica do tema passa um "aspecto de nebulosidade" impedindo abordagens conceituais mais refinadas. Segundo a autora, a abstração dos estudos acaba constituindo um discurso acadêmico cada vez mais distante da realidade docente. Ela defende a importância de sínteses teóricas para organizar o campo de estudos e redirecionar as questões levantadas nessas pesquisas (BORGES, 2001). O volume de trabalhos que identificam e categorizam os saberes docentes é extenso, demonstrando, por um lado, a importância desse tema para a área de formação de professores e, por outro, sua saturação. Precisamos, a partir do que já foi feito, avançar nas discussões e pensar em novas propostas de pesquisa, como a busca por consensos e a unificação entre tipologias.

Nesse sentido, visando otimizar as análises das categorias, aprofundar estudos sobre os processos de formação docente e avançar o debate sobre os saberes, propomos uma unificação entre tipologias de saber docente, com categorias emergentes das tipologias propostas por autores de referência na área. Após uma breve revisão da literatura, apresentamos nossa proposta em duas partes: primeiramente, em um movimento teórico, discutimos as similaridades entre as categorias de saber docente e apresentamos nossa proposta de unificação, no sentido de reunir em um todo único e homogêneo categorias similares; em seguida, ilustramos empiricamente essa unificação e discutimos suas implicações.

\section{OS SABERES DOCENTES NA FORMAÇÃO DE PROFESSORES DE CIÊNCIAS}

Alves (2007) se preocupou em entender como a área de formação docente tem recebido a temática. Ela concluiu que há poucos consensos entre os autores e diversas questões (epistemológicas, políticas e profissionais) estão em aberto. Borges (2001) colocou em evidência a diversidade, os contextos teóricos e metodológicos das correntes de pesquisa sobre os saberes dos professores, desvelando a pluralidade do tema. Monteiro (2001) discutiu a relação entre os professores e seus saberes em defesa das investigações sobre a epistemologia do conhecimento escolar e da prática docente, a pesquisadora apontou também semelhanças e desacordos entre Tardif, Shulman, Perrenoud, Chevallard e Develay. Nunes (2001) analisando a inserção do tema nas pesquisas brasileiras sobre formação de professores vem reforçar a pluralidade, as diferentes tipologias e o caráter polissêmico que envolve essa noção. Esses estudos, em sua maioria do início dos anos 2000 , sintetizam as principais pesquisas realizadas e anunciam a 
constituição de uma área de pesquisa que viria a se fortalecer no decorrer da década.

São múltiplos os estudos teóricos que resumem as tipologias e os modelos do saber docente. Buscando apreender as definições de saberes em uma perspectiva conceitual e tipológica para então refletir sobre a formação docente, Almeida e Biajone (2007) apresentam e comparam as categorias de Tardif, Gauthier e Shulman. Segundo eles, esses autores mantêm particularidades, apresentam similaridades, suas classificações são diferentes, porém "não tão singulares a ponto de serem excludentes" (ALMEIDA; BIAJONE, 2007, p. 290). Fernandez (2015) analisou criticamente os modelos existentes sobre a base de conhecimentos docentes na perspectiva de Shulman, propondo-se a fornecer um panorama para a literatura em ensino de Ciências. A autora encontra convergências e divergências entre os modelos, mas não propõe uma nova categorização, assim como propomos nesse artigo. Puentes et al. (2009) analisaram diferentes classificações e tipologias sobre os conhecimentos, saberes e competências necessários à docência e constataram uma proliferação de classificações e tipologias, que aumentam a complexidade do tema, tornando-o menos inteligível, além disso, apesar da diversidade de enfoques ser plural, o significado conceitual é semelhante entre os autores de tipologias do saber. Ribeiro e Gonçalves (2018, p. 993) esboçam uma "tentativa de diálogo" reconhecendo que há pontos de aproximação entre Shulman, Gauthier, Tardif e Pimenta. Entretanto, assim como os demais trabalhos supracitados, Ribeiro e Gonçalves (2018) não propõem novas categorias, apenas resumem as tipologias desenvolvidas pelos autores referenciados.

De modo complementar, são comuns estudos empíricos que utilizam as tipologias de saber docente na análise do discurso e da prática de professores. Goes (2014) fez um mapeamento de como o conhecimento pedagógico do conteúdo se insere na área de educação e ensino de Química, percebendo que mais de $80 \%$ dos trabalhos são empíricos e publicados em revistas científicas, sobretudo a partir dos anos 2000. Confortin e Caimi (2017) investigaram como se constituem e mobilizam os saberes de dois professores de Biologia, segundo a perspectiva teórica de Tardif e Gauthier e mediante o estudo da história de vida, de entrevista semiestruturada e da observação de aulas. Costa, Camargo e Silva (2018) identificaram a mobilização de dois tipos de saberes em licenciandos em Química a partir de uma atividade com material didático: saber preparar e dirigir atividades e saber selecionar os materiais didáticos. Braga (2018) levantou as percepções de licenciandos em Química acerca de seus conhecimentos para a prática docente, para a autora os licenciandos constroem saberes nas aulas teórico-práticas e nos estágios, e aos poucos vão percebendo o significado de "ser professor" e se interessando mais pela profissão. Nesse mesmo sentido, Lima e Kochhann (2018) constataram o papel dos saberes docentes na construção da identidade profissional de licenciandos. Fejolo, Passos e Arruda (2017) pesquisaram, através de entrevistas e observações de aulas, os tipos de saberes que um professor experiente comunica aos estudantes de licenciatura em Física durante uma atividade de supervisão utilizando as categorias propostas por Gauthier e colaboradores. Longhini e Hartwig (2007) analisaram a parceria entre um professor de Ciências experiente e um professor aspirante, tomando como princípio a base de conhecimentos para o ensino de Shulman. Zanon, Oliveira e Queiroz (2009) analisaram as visões de alunos de pós-graduação de química, por 
meio de um questionário, acerca das necessidades formativas de professores do ensino superior.

Há também trabalhos empíricos que buscam uma compreensão relacional das tipologias. Bozelli (2010) investigou a mobilização de saberes docentes em contextos interativos discursivos de ensino de Física envolvendo analogias. Acreditando na aproximação das perspectivas do saber docente em subconjuntos, sob o ponto de vista epistemológico, reduzindo-os em um número menor, a autora organizou as tipologias de diferentes autores (dentre eles Tardif, Gauthier e Shulman) em seis categorias de saber docente utilizadas na análise de sua tese. Finoqueto (2007) investigou os saberes mobilizados por professores por meio das categorias de Tardif, Gauthier, Shulman e Pimenta. A autora agrupou as tipologias desses autores em quatro grandes blocos utilizados na análise de sua pesquisa de mestrado. Em outro trabalho, Finoqueto, Santos e Terrazan (2005) analisaram os afastamentos e as aproximações entre as tipologias de Tardif, Gauthier, Shulman, Pimenta e Perrenoud. Em sua interpretação, há muito mais pontos de aproximação do que afastamentos e são possíveis as convergências entre todas as categorias propostas pelos autores (FINOQUETO; SANTOS; TERRAZAN, 2005).

Embora essas pesquisas não discutam diretamente ou proponham unificações das tipologias, elas nos ajudam a sustentar nossa proposta, pois apontam alguns caminhos de articulação entre as tipologias, revelam a indiferenciação entre os termos saber e conhecimento e reforçam que essa diversidade temática tem contribuído mais para fragmentar do que para pensar em uma agenda de pesquisa comum.

\section{PARA ALÉM DAS DIFERENÇAS: AS APROXIMAÇÕES TEÓRICAS ENTRE AS CATEGORIAS DE SABER DOCENTE}

Para a análise teórica assumimos as perspectivas de Maurice Tardif (2014; TARDIF; LESSARD; LAHAYE, 1991), Clermont Gauthier (1998) e Lee Shulman (1986a, 1986b, 1987) por serem os autores mais difundidos nas pesquisas brasileiras (ALMEIDA; BIAJONE, 2007; BORGES, 2001; NETO; COSTA, 2016; NUNES, 2001).

Cronologicamente, os estudos de Shulman são pioneiros, seguidos pelas pesquisas de Tardif e posteriormente Gauthier que aparece mais tardiamente, influenciado pela obra dos dois primeiros autores. Assim, as similaridades entre eles parecem ser uma consequência natural do processo de discussões da área, visto que esses autores não apresentam fortes divergências epistemológicas, são contemporâneos e desenvolveram algumas pesquisas em parceria. As primeiras traduções para o português correspondem aos textos de Tardif publicados no começo dos anos 1990, em especial um artigo de 1991 na revista Teoria e Educação em parceria com Lessard e Lahaye (LUDKE, 2001). Nos anos seguintes, o referido autor atuou como professor visitante no Brasil e sua obra, sobretudo o livro "Saberes docentes e formação profissional" que está na 17ạ edição, tem sido amplamente utilizado nas pesquisas brasileiras. Contemporâneo, o canadense Gauthier estuda as competências profissionais e a formação docente desde os anos 1980. Possui diversas publicações sobre a temática, inclusive muitas em parceria com Tardif. Sua obra mais difundida no Brasil é "Por uma teoria da Pedagogia: pesquisas contemporâneas sobre o saber docente" publicada pela 
primeira vez em 1998 ese encontra na terceira edição atualmente. Segundo Vieira e Araújo (2016), a inserção de Shulman nas pesquisas brasileiras parece ter sido mais tardia e restrita, embora o autor seja um dos mais conhecidos e respeitados pesquisadores em seu país e tenha trabalhado a questão dos conhecimentos para a docência desde o início dos anos 1980 (LUDKE, 2001). Um dos motivos pode ter sido a escassez de traduções de seus textos em comparação com as obras de Tardif e Gauthier.

Consideramos três argumentos para estruturar nossa proposta teórica que serão apresentados e desenvolvidos neste artigo nesta mesma ordem:

i. apesar da pluralidade terminológica os termos para se referir aos saberes são usados com a mesma acepção;

ii. as definições das categorias são semelhantes, pois partem dos mesmos princípios;

iii. as tipologias de cada autor têm suas particularidades, mas não são excludentes, possibilitando uma unificação entre elas.

\section{Pluralidade de termos: saber ou conhecimento?}

São diversos os termos usados para designar os saberes próprios à docência: saber, conhecimento, disposição, competência, aptidão, habilidades, crença, concepção, pensamento do professor, repertório de conhecimentos, etc. que são usados muitas vezes sem uma definição clara, reiterando a complexidade e a diversidade que envolvem a noção de saber docente (ALMEIDA; BIAJONE, 2007; BORGES; TARDIF, 2001; PUENTES et al., 2009; TARDIF, 2014).

Para Fernandez (2015, p. 503), apesar de serem muitas vezes usados como sinônimos esses termos provêm de duas correntes teóricas distintas: uma que opera pela "desmontagem analítica dos componentes envolvidos no conhecimento docente" e se aproxima dos trabalhos de Shulman; e outra que está associada à corrente teórica do "pensamento do professor" com forte influência de Schon e a epistemologia da prática, na qual estariam os trabalhos de Tardif e Gauthier. Segundo a autora o conhecimento é "a especialização do saber, ou seja, o conhecimento passa pela reflexão do saber fazer, elevando a prática a um nível de consciência, reflexão, análise, sistematização e intenção" (FERNANDEZ, 2015, p. 504). De modo semelhante, Roldão (2007) também identifica a existência dessas duas linhas na produção das pesquisas sobre o conhecimento profissional docente. Porém, diferentemente da primeira autora, Roldão (2007) enfatiza que há múltiplas versões no interior dessas linhas e uma análise mais detalhada pode indicar inúmeras aproximações permitindo estabelecer contato entre elas. Fiorentini e colaboradores (1998, p. 312) também diferenciam os termos, assumindo que conhecimento é algo próximo à "produção científica sistematizada e acumulada historicamente", possui regras rigorosas de validação aceitas pela comunidade científica; e o saber, por outro lado, estaria relacionado a um modo de "conhecer/saber mais dinâmico, menos sistematizado ou rigoroso" e mais articulado a formas de saber relativos à prática não possuindo normas rígidas de validação. No entanto, mesmo com essa distinção, os autores utilizam ambas as denominações sem uma diferenciação rígida, pois consideram que "nem mesmo 
os filósofos possuem uma posição clara sobre a diferenciação de significado destes termos" (FIORENTINI et al., 1998, p. 312).

Puentes et al. (2009) analisaram 11 autores referências para a temática, dentre eles Tardif, Gauthier e Shulman, e concluíram que o significado conceitual dos termos é praticamente o mesmo em todos os autores consultados. Ribeiro e Gonçalves (2018) reforçam que as pesquisas utilizam os termos conhecimento e saber sem distinção de significado. Cunha (2007) discute sobre as concepções de saber segundo perspectivas epistemológicas e filosóficas, acerca dos verbos saber e conhecer na produção do conhecimento e na definição de saber; apesar da discussão, o autor não reconhece diferenças entre os termos e usa como sinônimos. Também consideram como sinônimo os trabalhos de Neto e Costa (2016) e Bozelli (2010).

Além disso, é preciso considerar que o uso de diferentes termos pode ser resultado das traduções. No inglês, a palavra knowledge se refere a conhecimento e comumente se usa a expressão knowledge base empregada num sentido bem amplo para designar o conjunto de conhecimentos necessários à docência, da mesma forma a palavra know pode ser traduzida como conhecer ou saber. No francês o termo savoir, mais comumente utilizado, é traduzido como saber e connaissances como conhecimento. Aliás, o próprio português permite o uso de diversos sinônimos oriundos dessas traduções.

A literatura aponta para diferentes correntes sobre a temática, mas não há consenso sobre a distinção entre os termos saber e conhecimento nem sobre a impossibilidade de associá-los. Também não parece ser uma preocupação nas pesquisas a busca por uma diferenciação exata dos termos. Também não encontramos em Tardif, Gauthier e Shulman uma discussão aprofundada dessas definições. Shulman (1987) refere-se a um corpo de conhecimentos, habilidades, atitudes e disposições presentes no exercício da profissão como knowledge base for teaching (base de conhecimentos para o ensino). Gauthier et al. (1998, p. 18) também se referem ao knowledge base, entendendo-o num sentido amplo que pode englobar "todos os saberes do docente", mas usam a expressão "reservatório de conhecimentos" como equivalente "aquilo que a tradição anglo-saxônica costuma chamar de knowledge base". Já Tardif (2014, p. 10-11) faz uso do termo saberes docentes, cuja noção "engloba os conhecimentos, as competências, as habilidades (ou aptidões) e as atitudes, isto é, aquilo que muitas vezes foi chamado de saber, saber-fazer e saber-ser".

Desse modo, reconhecemos a legitimidade dessa discussão, mas entendemos que não há uma distinção clara e definitiva entre os termos, aspecto que reforça a criação de uma tipologia unificada do saber dos professores. Defendemos e utilizamos em nossas pesquisas os termos saber e conhecimento como sinônimos.

\section{Definições não tão distintas}

Tardif é o autor que faz uma caracterização mais detalhada do conceito de saber. Para ele, os saberes do professor "são uma realidade social materializada através de uma formação, de programas, de práticas coletivas, de disciplinas escolares, de uma pedagogia institucionalizada, etc.", mas são também, ao mesmo 
tempo os "saberes dele" (TARDIF, 2014, p. 16). Assim, o desafio para esse autor é situar o saber dos professores na interface entre o social e o individual.

O saber é social porque:

i. é partilhado por um grupo de agentes comuns (professores), que trabalham em uma mesma organização (escola) e que estão sujeitos aos mesmos condicionantes;

ii. se insere em um sistema que visa garantir a legitimidade e orientar sua definição e utilização;

iii. os objetos do ofício docente são sociais (sujeitos/alunos);

iv. é adquirido no contexto, em função de uma carreira e se constrói ao longo de uma história profissional na qual o professor aprende progressivamente com o seu ambiente de trabalho (Tardif, 2014).

O saber é social porque se manifesta através das relações complexas entre o professor e seus alunos e não é uma substância ou um conteúdo fechado em si mesmo.

Da mesma forma, o autor defende que o saber do professor é individual, pois depende da personalidade, da experiência pessoal e profissional dele, mas não reside em seu subjetivo, não é absolutamente pessoal e íntimo. Assim, o saber dos professores está assentado na profunda relação entre o que eles são e o que eles fazem. Além disso, os saberes são: temporais, por serem adquiridos ao longo do tempo e decorrerem de sua própria história de vida; plurais e heterogêneos, pois provêm de diversas fontes (universidade, vida pessoal, programas de ensino, experiências etc.); personalizados e situados, pois são marcados pelo contexto de trabalho no qual se manifestam e, por fim, os saberes carregam marcas do ser humano e estão sempre ligados a componentes éticos e emocionais dos sujeitos envolvidos (alunos, professores, comunidade) (TARDIF, 2014).

Outro aspecto da proposta de Tardif é a relação do saber dos professores ao que o autor chama de "exigência de racionalidade". Essa exigência fundamenta-se no pensamento de um sujeito racional, no ato de julgar e se baseia em argumentações, ou seja, em racionalizações. Nesse sentido, os saberes dos professores seriam seus pensamentos, ideias, juízos, discursos e argumentos usados de maneira racional para justificar um discurso ou ação pedagógica e o professor seria um profissional dotado de razão, não basta que ele faça bem alguma coisa para dizer que "sabe fazer", é preciso que ele saiba argumentar e fornecer razões que justifiquem seus atos (TARDIF, 2014). Assim, para Tardif (2014, p. 223), esses saberes seriam marcados pela "racionalidade concreta dos atores, por suas deliberações, racionalizações e motivações" e constituiriam a fonte de julgamentos, as escolhas e decisões tomadas pelo docente no exercício de sua prática. Eles seriam, de certo modo, um reservatório no qual "o professor vai buscar suas certezas, modelos simplificados de realidade, razões, argumentos, motivos, para validar seus próprios julgamentos em função de sua ação" (TARDIF, 2014, p. 201).

Para combater a ideia de um ofício sem saberes e de um saber sem ofício, Gauthier e colaboradores (1998, p. 28) propõem que o ensino consiste na "mobilização de vários saberes que formam uma espécie de reservatório no qual o professor se abastece para responder a exigências específicas de sua situação 
concreta de ensino". Essa ideia é semelhante ao proposto por Tardif (2014), ambos os autores relacionam a natureza do saber à ideia de racionalidade. Dessa forma, os saberes docentes englobam "os conhecimentos, os discursos e as ações cujos agentes (pesquisadores ou professores) podem apresentar razões que os justifiquem" (GAUTHIER et al., 1998, p. 341). O professor é visto como um prático dotado de razão, ele "age e sabe (ou pode saber) porque o faz: sua ação se baseia em motivos justificáveis pela razão" (GAUTHIER et al., 1998, p. 341). Em sala de aula, o professor vivencia diferentes situações e contextos e deve tomar decisões que visem seus objetivos pedagógicos. Essa capacidade de decidir implica um julgamento, por parte do docente, de seus próprios atos e os de seus alunos, assim, sua ação depende dessa habilidade de julgar e esse julgamento se apoia em saberes, ou seja, nas razões que o orientam a julgar (e agir) num sentido ou no outro (GAUTHIER et al., 1998). O professor não é apenas alguém que aplica os saberes produzidos por outros, na verdade, ele constrói grande parte de seu saber na e para a ação, assim, seus julgamentos são todos voltados para a ação que será realizada pelo outro, o aluno (GAUTHIER et al., 1998; TARDIF, 2014).

Encontramos em Gauthier e colaboradores (1998, p. 344) e em Tardif (2014, p. 219) os seguintes aspectos que caracterizam os saberes docentes: i) são adquiridos principalmente numa formação universitária específica; ii) sua aquisição está associada a uma socialização profissional e a uma experiência da prática docente; iii) são mobilizados/utilizados em uma instituição específica, a escola e, portanto, estão ligados ao contexto e às necessidades dessa instituição; iv) são utilizados no âmbito de um trabalho singular: o ensino.

Em relação à perspectiva de Shulman, este autor assume que existe um corpo de conhecimentos e habilidades necessárias para o ensino e que estes são desenvolvidos ao longo da profissão, a esse conjunto de saberes ele chamou de knowledge base for teaching. Gauthier et al. (1998) também consideram o uso tradicional do termo knowledge base, mas optaram pela expressão "reservatório de conhecimentos" num sentido mais amplo devido à possibilidade de incluir dentro desse reservatório outros subconjuntos de saberes.

Para Shulman, essa base vai sendo construída ao longo da carreira a partir de diversas fontes, como: os conteúdos de áreas específicas do conhecimento; os materiais e as estruturas organizacionais (currículo, livros escolares, organização e estrutura da escola etc.); a literatura sobre o ensino, aprendizagem, aspectos sociais e filosóficos da educação e através da sabedoria da própria prática docente (SHULMAN, 1987). Mizukami (2004) acrescenta que essa base envolve conhecimentos de diferentes naturezas indispensáveis para a atuação profissional, além disso, esses conhecimentos são diversificados, flexíveis e se tornam mais aprofundados a partir da reflexão da experiência profissional.

Analisando essas três propostas percebemos que o sentido adotado para o conceito de saber (ou conhecimento) é semelhante para os três autores. Tardif defende a pluralidade e heterogeneidade do saber e o estudo da epistemologia da prática profissional; Gauthier estabelece uma teoria geral da pedagogia ao conceber o ensino como a mobilização de vários saberes que compõem uma espécie de reservatório; e Shulman investiga os conhecimentos dos professores sobre os conteúdos e a forma como eles se traduzem em sala de aula. Todos admitem que há um corpus de saberes necessários para a atuação profissional do professor, que estes são plurais, construídos em diferentes momentos formativos 
e que são mobilizados no exercício da profissão para orientar a prática docente. Com base nesses princípios, cada autor propõe uma tipologia para o saber dos professores, mas que não são discrepantes e possuem aspectos em comum, discutiremos a seguir essas similaridades e especificidades.

\section{RELAÇÃO ENTRE AS TIPOLOGIAS: UMA PROPOSTA DE UNIFICAÇÃO}

Uma segunda aproximação teórica entre os saberes dos professores se dá em relação às tipologias: elas são diferentes, mas não excludentes. Para Tardif (2014), em sua atividade profissional o professor dispõe de diversas formas de saber, provenientes de diferentes fontes, para se apoiar e agir. Esses saberes podem ser divididos em cinco tipos: (1) disciplinares, são aqueles estabelecidos pela instituição universitária e correspondem aos conteúdos que serão ensinados; (2) curriculares, relacionados aos objetivos, conteúdos e métodos provenientes dos programas e materiais escolares; ( 3 ) da formação profissional, referente ao que foi aprendido no curso de formação de professores (inicial ou continuada); (4) culturais, são herdados de sua trajetória de vida e de sua cultura particular e (5) experienciais, que surgem com a experiência do docente e são incorporados pela prática.

Na perspectiva de Gauthier, o reservatório seria composto por um conjunto de seis saberes: (1) disciplinares, se referem aos conteúdos diversos que serão ensinados; (2) curriculares, correspondem aos programas de ensino; (3) da ciências da educação, relacionados ao conhecimento profissional específico; (4) da tradição pedagógica, relativos a maneira de dar aulas; (5) experienciais, oriundos da prática pessoal do professor e os (6) saberes da ação pedagógica que se referem ao saber experiencial tornado público e validado pelas pesquisas (GAUTHIER et al., 1998).

Shulman (1987) apresenta sete categorias de conhecimentos para o ensino: (1) content knowledge (conhecimento do conteúdo) que se refere ao conteúdo a ser ensinado; (2) curriculum knowledge (conhecimento do currículo) referente aos materiais e programas escolares que servem de ferramentas aos professores; (3) general pedagogical knowledge (conhecimento pedagógico geral) relacionado as principais abordagens e estratégias para uso em sala de aula; (4) knowledge of educacional ends (conhecimento dos fins educacionais) que são as propostas, os valores, a história e filosofia da educação; (5) knowledge of contexts (conhecimento do contexto) referente aos conhecimentos do contexto escolar; (6) knowledge of learners (conhecimento dos alunos) que traduzem o conhecimento sobre os alunos e por fim o (7) pedagogical content knowledge (conhecimento pedagógico do conteúdo - PCK) relacionado a uma complexa amálgama na qual articulam-se aspectos do conteúdo curricular e da didática, representa o conhecimento da disciplina para o ensino e se manifesta na forma particular de trabalho do professor sobre um determinado conteúdo.

Monteiro (2001) declara que apesar de Shulman ter desenvolvido suas pesquisas anteriormente à Tardif é possível encontrar semelhanças entre suas tipologias, como o fato de ambos reconhecerem as categorias de conhecimento das disciplinas, pedagógicos e curriculares, assim como os saberes da prática. Além disso, para a autora, Shulman desenvolveu uma tipologia bastante elaborada e trouxe importante contribuição ao oferecer instrumentos para investigar a ação dos professores. Acrescentamos a essas discussões as contribuições de Gauthier 
que, comparado às categorias desses autores, apresenta uma definição conceitual muito próxima de Tardif.

Com base na nossa leitura de Tardif, Gauthier e Shulman e da literatura da área propomos a unificação de algumas tipologias que emergem de categorias já existentes. Dentre as múltiplas tipologias, percebemos algumas similaridades. São essas similaridades que permitem unificá-las, no sentido de reunir em um todo único e homogêneo, considerando as possíveis aproximações de categorias que antes estavam separadas. Comparando as tipologias desses autores notamos três grandes categorias de saber docente que se repetem em suas propostas: disciplinar, curricular e pedagógico.

O saber disciplinar para Tardif e Gauthier se refere aos conteúdos aprendidos nas disciplinas universitárias. De forma complementar, está presente em Shulman como conhecimento do conteúdo, que diz respeito aquilo que o professor deve dominar, os fatos e os conceitos de um determinado conteúdo, e ao entendimento da forma como ele é estruturado. Para todos os autores, o professor não produz esse saber e ele é adquirido através dos cursos de formação por meio das disciplinas oferecidas pelos departamentos universitários. Dessa forma, entendemos que o saber disciplinar se refere aos conteúdos próprios da matéria (ou disciplina) que será ensinada e são adquiridos nos cursos de formação inicial e continuada. De modo semelhante, Finoqueto (2007) reuniu o conhecimento do conteúdo de ensino de Shulman, o saber disciplinar de Gauthier e os saberes disciplinares de Tardif como um bloco de categorias em comum. Bozelli (2010) agrupou em uma categoria denominada saberes dos conteúdos as seguintes tipologias: o conhecimento do conteúdo específico de Shulman; os saberes disciplinares de Tardif e o saber disciplinar de Gauthier e colaboradores.

O saber curricular para Tardif (2014, p. 38) diz respeito aos "discursos, objetivos, conteúdo e métodos" utilizados pela instituição escolar na forma de programas. Para Gauthier, esses saberes compõem os programas escolares, não são produzidos pelos professores e são encontrados na forma de manuais, cadernos, livros ou apostilas (GAUTHIER et al., 1998). Shulman $(1987$, p. 8) acrescenta que o saber curricular inclui o domínio dos materiais e programas que servem como "ferramentas de trabalho" para o professor planejar e avaliar suas atividades. Infere-se que, para os três autores, o saber curricular envolve conhecer os programas de ensino, os materiais e documentos oficiais utilizados pela escola e podem ser adquiridos em cursos de formação inicial e/ou continuada e no exercício da profissão. Sustentando a nossa proposição encontramos aproximações teóricas em Finoqueto (2007) e Bozelli (2010). Finoqueto (2007) agrupou o conhecimento do currículo de Shulman, os saberes curriculares de Tardif e o saber curricular de Gauthier como um conhecimento/saber que se refere aos discursos, objetivos, conteúdos e métodos. Bozelli (2010, p. 50) reuniu como saberes curriculares o saber curricular de Tardif, o conhecimento sobre o currículo de Shulman, e considera esse saber como "mais um dos saberes pertencentes ao repertório de conhecimentos" de Gauthier e colaboradores (1998).

Certas tipologias são mais numerosas e apresentam denominações diversas, com base na nossa interpretação dos autores que lemos escolhemos unir como saber pedagógico algumas tipologias com denominações diferentes, mas que continham em si a mesma essência: noções sobre o conhecimento pedagógico ou educacional específico, relativo ao ensino. 
Agrupamos nessa categoria os saberes da formação profissional de Tardif (2014, p. 36-37), pois são aqueles "transmitidos pelas instituições de formação de professores" e que fornecem um "arcabouço ideológico à profissão", "algumas formas de saber fazer e algumas técnicas". Os saberes da ciência da educação e da tradição pedagógica de Gauthier e colaboradores (1998, p. 31) também fazem referência a um "saber profissional específico" que "permeia a maneira de o professor existir profissionalmente", serve de guia para as atitudes do professor e constitui o "saber dar aulas", por isso, esses saberes foram também incluídos nessa categoria. Dentre as tipologias de Shulman, reunimos quatro: os conhecimentos pedagógicos gerais, os conhecimentos dos fins educacionais, os conhecimentos do contexto e os conhecimentos dos alunos, pois, essas categorias abrangem um conhecimento pedagógico global como conhecer diferentes abordagens de ensino, compreender as características dos alunos e o contexto escolar, etc. Portanto, compreendemos o saber pedagógico como um saber amplo que engloba as noções relativas ao ensino, como o funcionamento da escola; a compreensão acerca do comportamento e desenvolvimento dos alunos; o conhecimento sobre estratégias e abordagens de ensino; os fundamentos filosóficos, históricos e pedagógicos da educação, etc.

Com base em Gauthier entendemos que a prática docente é complexa e dinâmica e influencia no desenvolvimento e na mobilização de todos os saberes do professor. O saber pedagógico (e outros) pode ser aprendido e aprimorado no decorrer da prática profissional. Essa categoria não inclui o saber da experiência de Tardif, nem a ação pedagógica de Gauthier e nem o conhecimento pedagógico do conteúdo (PCK) de Shulman. Diferentemente do saber da experiência o saber pedagógico contém aspectos teóricos, aprendidos nas disciplinas pedagógicas dos cursos de licenciatura. Já os saberes da experiência, como proposto por Tardif (2014, p.54) são formados por todos os outros saberes e "retraduzidos, polidos e submetidos às certezas construídos na prática e na experiência" profissional de cada docente.

Além disso, segundo Tardif e Shulman os saberes pedagógicos são transmitidos pelas instituições, cursos de formação inicial e continuada de professores e Gauthier inclui também o exercício da profissão e a socialização escolar pré-profissional (anterior ao curso de formação para a docência, na vivência enquanto aluno da escola) do docente como fonte de aquisição. Finoqueto (2007) reúne algumas das tipologias como um bloco comum, sendo: os saberes da formação profissional de Tardif; o saber das ciências da educação de Gauthier e o conhecimento pedagógico geral de Shulman. Bozelli (2010) criou a categoria saberes pedagógicos gerais com as tipologias: saber das ciências da educação de Gauthier; o conhecimento pedagógico geral de Shulman e os conhecimentos teóricos e práticos da pedagogia (saberes da formação profissional) de Tardif.

Considerando essas discussões, apresentamos uma proposta de unificação dos saberes docentes, resumidas no Quadro 1 , contendo as definições e as principais, porém não únicas, fontes de aquisição desses saberes. 
Quadro 1- Tipologias de saberes docentes unificadas a partir dos autores analisados

\begin{tabular}{|c|c|c|c|}
\hline & \multicolumn{3}{|c|}{ Tipologias de saber } \\
\hline & Saber disciplinar & Saber curricular & Saber pedagógico \\
\hline Definição & $\begin{array}{l}\text { Constituem os } \\
\text { conteúdos que } \\
\text { serão ensinados. } \\
\text { É o “saber a } \\
\text { matéria”. }\end{array}$ & $\begin{array}{l}\text { Formado pelos } \\
\text { programas de ensino, } \\
\text { materiais, métodos e } \\
\text { documentos oficiais. É o } \\
\text { "conhecer o currículo". }\end{array}$ & $\begin{array}{l}\text { Compõe o conhecimento } \\
\text { profissional específico, } \\
\text { relativo ao ensino. É o } \\
\text { "saber ensinar". }\end{array}$ \\
\hline $\begin{array}{l}\text { Principais } \\
\text { fontes de } \\
\text { aquisição }\end{array}$ & $\begin{array}{c}\text { Cursos de } \\
\text { formação, } \\
\text { principalmente a } \\
\text { inicial. }\end{array}$ & $\begin{array}{l}\text { Cursos de formação e } \\
\text { exercício da prática } \\
\text { docente. }\end{array}$ & $\begin{array}{l}\text { Período pré-profissional, } \\
\text { cursos de formação e } \\
\text { exercício da prática } \\
\text { docente. }\end{array}$ \\
\hline
\end{tabular}

Fonte: Autoria própria (2020).

Esses autores compartilham categorias e percepções semelhantes sobre os saberes docentes, sintetizadas no Quadro 1. Defendemos que as três categorias propostas aqui são basilares e fundantes por reunirem as principais ideias desses autores acerca do conhecimento profissional docente. No entanto, apesar desse esforço de unificação, reconhecemos que existem especificidades relacionadas à prática e à experiência profissional docente e que são desenvolvidas em profundidade por cada um desses autores. Não desconsideramos a significativa contribuição saber da experiência na perspectiva de Tardif, do saber da ação pedagógica da obra de Gauthier, e do esforço de Shulman para recuperar o paradigma perdido nas profundas discussões sobre o PCK. No entanto, elas não foram o foco da nossa discussão e não estão incluídas nas categorias que propomos.

Nossa análise mostra as similaridades entre perspectivas diferentes no complexo universo que permeia os saberes relativos à docência e que a aproximação entre vertentes aparentemente distintas pode esclarecer aspectos ainda pouco conhecidos sobre o desenvolvimento e a mobilização de saberes. As pesquisas desenvolvidas por Bozelli (2010) e Finoquetto (2007) vem corroborar a proposta de unificação de tipologias. Para evidenciar e validar essa discussão, utilizamos essas categorias na análise de professores de Química, apresentada a seguir.

\section{UMA INTERPRETAÇÃO EMPÍRICA COM A TIPOLOGIA UNIFICADA DO SABER DOCENTE}

$\mathrm{Na}$ segunda parte deste artigo, para ilustrar empiricamente e validar a unificação proposta analisamos os saberes docentes de três professores. Nossos sujeitos integram uma pesquisa mais ampla que investiga em profundidade a trajetória profissional de professores de Química. Selecionamos para este artigo três desses professores: Rui, Clara e Sofia. Eles estão em início de carreira, são formados em um mesmo curso de licenciatura e têm trajetórias pessoais e profissionais diferentes. Rui tem 32 anos, cursa o Mestrado em Química, é docente há cinco anos em escolas particulares lecionando para o ensino médio, cursinho e cursos técnicos, teve uma breve experiência em escolas públicas e leciona principalmente Matemática e Física. Clara tem 34 anos, é mestre em Química e leciona como professora efetiva da rede estadual de ensino há sete anos a 
disciplina de Química para o ensino médio. Sofia tem 30 anos, leciona como professora substituta de exatas para o ensino fundamental e médio em escolas públicas há cinco anos.

Para a coleta de dados observamos aulas e fizemos entrevistas individuais semiestruturadas que orientaram a identificação dos saberes docentes. Seguindo os preceitos éticos para o desenvolvimento da pesquisa, os participantes assinaram um Termo de Consentimento Livre e Esclarecido e foram informados sobre os objetivos, riscos e benefícios da pesquisa. Adotamos nomes fictícios para preservar o anonimato.

Primeiramente, realizamos observações de duas a três aulas para verificar como os docentes atuam no seu dia a dia em sala de aula. Esse método investigativo é fundamental para analisar o "modo como as pessoas percebem, explicam e descrevem a ordem no mundo que habitam" (BOGDAN; BIKLEN, 1994, p. 60). Dessa forma, percebemos como os professores concebem suas próprias ações, construindo e ressignificando seus saberes. Utilizando um roteiro prédefinido observamos a condução da aula (gestão do tempo e organização do espaço/turma; gestão do conteúdo; materiais, recursos, estratégias e avaliações utilizadas; planejamento da disciplina etc.) e as relações estabelecidas entre alunos, professores, conteúdo e escola. Os dados foram coletados em 2016, por meio de vídeo-gravações e de anotações em diários de campo, essas anotações eram divididas em três etapas: descrição dos momentos observados; conversas realizadas com os docentes após as observações; reflexões e comentários da pesquisadora sobre o observado. Para Tardif (2014), a observação é uma maneira fundamental de compreender os saberes profissionais dos docentes. Pode-se estudar o que um ator sabe fazer por meio de seu discurso e através da observação e descrição de sua atividade, registando também as regularidades das ações dos atores, suas práticas objetivas e seus múltiplos componentes (TARDIF, 2014).

Após as observações fizemos uma entrevista com cada docente, com duração de aproximadamente uma hora e meia cada. Seguimos um roteiro pré-definido e organizado em torno de quatro tópicos: i) trajetória escolar pré-profissional, para verificar a influência das vivências enquanto aluno da educação básica na atuação como docente; ii) formação inicial, investigando como as disciplinas, a convivência com outros docentes, os estágios e as atividades extracurriculares influenciam a prática docente; iii) experiência profissional, para entender como as experiências com a docência contribuíram para formá-los enquanto professores; iv) questões específicas sobre o saber docente.

O roteiro incluía questões mais reflexivas (como: "O que a experiência profissional te ensinou sobre ser professor?") e sobre as ações realizadas pelos docentes, suas atitudes e intervenções verificadas durante a observação, desejávamos que justificassem suas ações e fornecessem razões discutíveis e criticáveis sobre o seu discurso. Pois, assim como Tardif consideramos que

se questionarmos o outro a respeito de suas próprias ações, permitindo-lhe que as explique que nos diga o porquê de seu agir, ele será obrigado a explicitar, através de suas razões de agir, os saberes nos quais se baseia para agir assim (TARDIF, 2014, p. 202).

O trabalho empírico contribuiu para validar a teoria e perceber a necessidade de unificar as tipologias. As categorias de saber são conceituais, no sentido de 
serem construídas no decorrer da análise da prática docente e não entendidas como naturais ou inatas. Assim, primeiramente, partimos das transcrições das entrevistas, dos diários de campo e dos vídeos das aulas buscando identificar nas falas e nas ações dos professores elementos da teoria dos saberes docentes, como as fontes ou experiências que influenciaram no seu desenvolvimento, sua mobilização e as especificidades desses conhecimentos. Nesse momento da análise estávamos pautadas na teoria de Tardif, Gauthier e Shulman. Nos vimos diante dos questionamentos: sendo as tipologias desses autores tão próximas, qual categoria reflete melhor os saberes percebidos nos sujeitos? Como e por que escolher um único autor? Não seria artificial buscar uma vinculação única diante de categorias tão próximas?

Já havíamos percebido teoricamente muitas aproximações entre esses autores (como apresentado na seção anterior desse artigo), e no movimento de análise percebemos que havia mais similaridades do que discrepâncias entre as tipologias. Assim, sentimos a necessidade de repensar as tipologias, buscar consensos e unificá-las. Voltamos para o estudo teórico desses autores e, em paralelo com a análise empírica, definimos as três categorias de saber: disciplinar, curricular e pedagógico. Então, associamos as falas e ações dos docentes com as características dessas três categorias, conforme a nossa proposta sintetizada no Quadro 1. Identificamos também os saberes experienciais, os da ação pedagógica e o PCK, no entanto, mesmo reconhecendo sua importância para a prática docente, por não ser o foco desse texto, não discutiremos esses saberes. Considerando nosso objetivo de defender as categorias unificadas, apresentaremos a seguir a análise dessas três categorias, identificadas em todos os sujeitos. Além de categorizar os saberes dos professores mostraremos como esses conhecimentos são constituídos e mobilizados em cada docente, ilustrando empiricamente a fecundidade da unificação tipológica que propomos.

\section{SABER DISCIPLINAR}

Os saberes disciplinares, segundo nossa proposta, são aqueles que envolvem os conteúdos a serem ensinados e são aprendidos principalmente na formação inicial. Os saberes são constituídos e mobilizados de modo diferente nos professores desse estudo em função das diferentes vivências na licenciatura em Química, sobretudo em relação à estrutura curricular. Clara passou por um currículo mais antigo do curso cujo foco eram as disciplinas científicas, Rui e Sofia cursaram uma estrutura curricular com mais disciplinas pedagógicas.

Esse saber é percebido algumas vezes na fala da professora Clara. Durante a graduação ela dedicou-se praticamente apenas às disciplinas científicas, sendo considerada uma excelente aluna, fez iniciação científica e teve pouco contato com a área de ensino. Assume que todo o conhecimento adquirido, "meu embasamento teórico", foi na universidade, reconhecendo esse espaço como uma fonte para os saberes disciplinares, assim como definido em nossa proposta em concordância com Tardif, Gauthier e Shulman. Quando questionada sobre o que um professor precisa saber para poder lecionar, Clara afirma enfaticamente que "primeiro ele precisa saber o conteúdo".

Ao contrário de Clara, Sofia destacou pouco o saber disciplinar como sustentação de sua ação docente, em comparação com os outros saberes. Ela teve 
dificuldades ao cursar as disciplinas na licenciatura, apesar disso, consulta livros do ensino superior para preparar suas aulas ou atividades,

\begin{abstract}
"eu tenho que voltar muito nos livros, inclusive no Atkins, porque eu acho interessante a gente saber a forma do ensino superior pra voltar pro básico [...] se eu não souber [o conteúdo], não tenho como ensinar o básico para o meu aluno, porque surgem perguntas e às vezes, eu tenho que sair do básico para responder".
\end{abstract}

Essa percepção de Sofia reitera a formação inicial como fonte de aquisição dos saberes disciplinares, ela recorre ao material utilizado no curso de licenciatura por considerá-lo como um apoio seguro para preparar suas aulas, isto é, um conhecimento legítimo e necessário para sua atuação profissional.

Em Rui, esse saber também é pouco destacado. Ele foi um aluno mediano durante a licenciatura e tinha dificuldade com as disciplinas científicas. A mobilização do saber disciplinar em sua prática decorre principalmente da vivência como professor substituto, tendo que lecionar outras disciplinas além da Química para complementar sua carga horária. Ao planejar as aulas de Matemática, disciplina que mais leciona, ele utiliza os livros de cálculo da graduação; quando leciona para o curso técnico usa os conteúdos vistos na disciplina de computação na licenciatura; e em relação às aulas de Química, prepara "a aula do Atkins, vejo os conteúdos importantes, estilo graduação, estilo do jeito que eu aprendi". Interessante notar nesse professor uma relação diferente com o saber disciplinar de Matemática e Química. Rui tem mais experiência lecionando Matemática e teve mais contato com essa disciplina quando fez cursinho e no ensino médio. Assim, ele sente-se mais seguro para ensinar conteúdos de matemática, "eu tive a matemática da segunda série até o colegial. A minha segurança maior em determinados assuntos é na matemática porque eu vi mais [...] A química eu tive no cursinho, memorizei, fiz vestibular e vi aqui [na universidade]". Para ele, o fato de ter estudado Matemática na educação básica é suficiente para ensiná-la. Por outro lado, em relação à Química observamos que apesar de ter estudado em profundidade, Rui ainda possui lacunas que acredita poder ser superadas com outros cursos, assim, o saber disciplinar de química é escasso em sua formação, tanto que Rui faz poucas menções a esse saber durante a entrevista. Dessa forma, essa "deficiência" de conteúdo e a falta de prática em lecionar química, provocou em Rui insegurança para ensinar a disciplina para o qual foi formado.

Apesar de o saber disciplinar ser pouco destacado na atuação desses professores, com exceção de Clara, conforme observamos em suas aulas e na entrevista, quando questionados diretamente os três professores revelam que o saber disciplinar é aquele fundamental para exercer sua função docente, logo, "saber a matéria" é considerado por eles (e pelo curso) o requisito mais importante em sua profissão.

\title{
Saber curricular
}

Os saberes curriculares, segundo nossa proposta, são formados pelos programas de ensino, materiais, métodos e documentos oficiais mobilizados pelo professor em sua prática profissional. São aprendidos nos cursos de formação inicial e principalmente na vivência da profissão ao se depararem com os currículos 
escolares, com os projetos pedagógicos, as apostilas e os livros didáticos. Todos os docentes investigados demonstram mobilizar esse saber, embora com algumas nuances.

Lecionando química há cinco anos em única escola, Clara demonstra conhecer e seguir os programas de ensino e as regras da escola que exigem o uso do material, "eu pego questões do ENEM, que eu acho mais próximo do currículo deles, tem um contexto na questão [...] não sigo muito o livro didático, porque ele não segue o currículo do Estado [...] o foco é o currículo que a gente tem que seguir". Clara faz uso do material curricular como uma ferramenta de trabalho para planejar e realizar as atividades, ela adequou-se às exigências do seu ambiente de trabalho, tendo incorporado esse saber, mobilizando-o em sua rotina docente.

Por outro lado, Sofia tem uma visão mais crítica de seu saber curricular. Ela tem dificuldade para trabalhar com o material das escolas estaduais (o mesmo utilizado por Clara), pois o considera "incompleto [...] muito fraco", então ela adapta o conteúdo desse material à sua forma de lecionar. Essa postura de Sofia relaciona-se a aspectos caracterizadores do saber curricular, segundo nossa proposta unificada, como conhecer o programa de ensino (currículo), usá-lo como guia para planejar suas atividades e ser capaz de criticá-lo ou sugerir adequações. Durante a licenciatura Sofia participou do PIBID e de outras experiências voltadas ao ensino de Ciências. Pressupomos que essas vivências fomentaram uma atitude mais crítica e reflexiva de sua prática. Além disso, por ser uma professora substituta ela trabalhou em diferentes escolas com diferentes materiais, o que enriquece seu saber curricular.

Em relação ao professor Rui, observamos assim como em Clara a referência aos materiais escolares como constitutivos desse saber, sem muita avaliação. Sobre o preparo das aulas, ele afirma que: "eu pego a apostila deles e adapto [...] preparo uma aula mais aprofundada e depois vou editando, como se fosse um trailer de um filme. Eu monto todo o filme, todo o roteiro e depois vou adaptando segundo a referência", mostrando que conhece o material, procura segui-lo e adapta conforme as exigências da escola e dos alunos. Entretanto, o saber curricular para esse professor está pautado na repetição e reprodução do material de ensino, de modo pouco crítico, de acordo com as exigências da escola e adaptado ao público quando necessário.

\section{Saber pedagógico}

O saber pedagógico, segundo nossa proposta, se refere ao conhecimento profissional específico do professor, relativo ao ensino. As fontes de aquisição desse saber são diversas, incluem o período pré-profissional no qual os docentes ainda eram alunos, os cursos de formação inicial, por meio das disciplinas pedagógicas, e o exercício da prática docente. Percebemos manifestações diferentes nos docentes investigados que, apesar dessa divergência, mantém os elementos constitutivos desse saber.

O início da docência para Clara foi problemático, um "choque cultural", ela se sentia "despreparada" e insegura para lecionar: "me formei como professora, mas não me sentia professora!". O conteúdo ela "tirava de letra", mas não sabia como agir em sala de aula, como interagir com os alunos, isto é, ela dominava o saber 
disciplinar, mas sentia-se insegura em relação ao saber pedagógico. Essa insegurança está relacionada à sua formação inicial que, segundo seu discurso, foi falha em relação aos saberes pedagógicos. Na graduação teve poucas experiências com o ensino, nada muito relevante segundo ela, cita a disciplina de psicologia da educação que tinha uma visão mais "humanística" do ensino e a de instrumentação para o ensino de Química, na qual aprendeu estratégias para usar em sala de aula. No entanto, esses momentos não parecem ter se constituído em fontes de saberes pedagógicos, nem mesmo os estágios obrigatórios do curso. Para Clara, eles foram "meio conturbados", pois os alunos iam para a escola sem orientação e as experiências vividas foram mais como "um exemplo do que eu não deveria fazer" do que momentos de aprendizagem. Segundo ela, há "uma lacuna entre a escola pública e a universidade" e é recorrente em sua fala essa discrepância entre teoria e prática.

Por outro lado, para Sofia a formação inicial teve importante papel no desenvolvimento do saber pedagógico. Em sua perspectiva, os estágios não foram tão eficazes, apenas no final do curso ela pôde aprender "a teoria antes da prática", apesar disso, para ela, as melhores disciplinas foram as pedagógicas, que the deram certeza sobre a escolha da docência. Essa professora tem uma grande admiração e paixão pela profissão, seu interesse pela profissão surgiu ainda na infância por influência da mãe professora e pela relação afetuosa que teve com professores da educação básica. As atividades voltadas para o ensino, desenvolvidas durante a graduação como projetos de extensão em museus de ciências, participação em eventos de educação e o PIBID, reforçaram em Sofia sua motivação para a docência e sedimentaram aspectos de seu saber pedagógico. Ela considera que, primeiramente, um professor deve dominar o conteúdo (saber disciplinar) e, em segundo lugar, é preciso "saber como transmitir esse conteúdo para o aluno [...] essa questão de como você vai passar para o aluno é importante. [..] os improvisos, dessas situações, de rotina".

Nessa fala encontramos aspectos do saber pedagógico, no sentido desse saber poder fornecer maneiras, técnicas e formas de saber-fazer para essa professora, conforme definido na proposição dessa tipologia. Esse saber também está presente no professor Rui, mas não é tão valorizado como em Sofia. Na graduação ele também participou do PIBID, entrou no projeto acreditando que lá iria "aprender a dar aula mesmo". Com essa experiência Rui teve contato com diferentes escolas e alunos, constituindo seus conhecimentos sobre o contexto escolar, as características dos alunos e os aspectos que vão além do saber disciplinar. Esse aprendizado é considerado um saber-fazer pedagógico e foi fundamental para o aprendizado profissional desse professor. Percebemos que apesar das experiências formativas serem semelhantes para Rui e Sofia, cada docente constitui e mobiliza o saber pedagógico de um modo particular segundo suas vivências pessoais e profissionais.

Essa breve análise ilustra as três categorias de saber propostas aqui: disciplinar, curricular e pedagógico, que unificam as tipologias de Tardif, Gauthier e Shulman e constituem-se como uma ferramenta analítica para estudar os conhecimentos profissionais dos professores. 


\section{CONSIDERAÇÕES FINAIS}

As inúmeras pesquisas realizadas sobre os saberes dos professores desde os anos 1980 cumpriram um papel histórico importantíssimo para a área de formação docente, no entanto, as demandas atuais desse campo de pesquisa são outras e exigem a proposição de novos caminhos, como a busca por consensos teóricos. Assim como Finoqueto, Santos e Terrazan (2005) acreditamos que reconhecer a existência de saberes é imprescindível para a discussão do trabalho docente, porém, não é suficiente. A prática docente é uma atividade complexa e envolve, ao mesmo tempo, a mobilização de diferentes saberes. Classificar as falas e ações dos professores em um saber $X$ ou $Y$ é analiticamente desejável, visto que pode facilitar o processo de análise e permitir a melhor compreensão do todo a partir de cada componente. As tipologias sistematizam e organizam a complexidade da prática do professor, elas não são estanques ou absolutas, uma mesma ação ou discurso docente pode abarcar diferentes saberes, a categorização atende a fins analíticos e a objetivos didáticos e formativos. Entretanto, ao empreender um grande esforço na categorização e vinculação teórica artificial a um único autor desvia-se os esforços de análises mais aprofundadas sobre os processos formativo. Acreditamos que a fragmentação e a pluralidade dessas categorizações comprometem uma análise integral desse processo, e que os saberes devem ser considerados em conjunto, como complementares e contextualizados.

Desse modo, propomos a unificação de tipologias contemplando as demandas da análise e permitindo ao investigador se debruçar de modo mais detido sobre o processo formativo como um todo ao invés de empenhar-se em diversas denominações, classificações ou vinculações teóricas. A proposição de uma tipologia unificada permite: i) operacionalizar o seu uso; ii) reconhecer consensos na área de pesquisa; iii) perceber e focar em outros elementos formativos associados aos saberes. A redução do número de tipologias (de 13 para 3, neste caso) explicita consensos teóricos que representam importantes avanços na análise das práticas docentes e permite o estudo aprofundado dos elementos constitutivos de cada categoria. Diminuindo o esforço de apenas categorizar os saberes, pode-se ir além da categorização descritiva e mudar o foco para o processo formativo, à luz de outras teorias mais amplas investigando: a constituição, a mobilização e as implicações do saber para a prática docente; as relações entre os saberes disciplinares, curriculares, pedagógicos e outros; a influência da trajetória pessoal-profissional do professor nos seus saberes; a relação dos saberes com a identidade e/ou desenvolvimento profissional; a associação entre os saberes e as crenças, as disposições, as capacidades do professor e as representações sobre a profissão etc.

Nesse sentido, citamos como exemplo a pesquisa de Bozelli (2010) que, ao sintetizar as tipologias de saber docente, pôde investigar o processo de ensino e aprendizagem, o uso de analogias pelos docentes e as interações discursivas em sala de aula. Finoqueto, Santos e Terrazan (2005) também se debruçam sobre o desenvolvimento profissional a partir da síntese de tipologias de saber docente. Bem como Agostini e Massi (2017) que partem de tipologias unificadas para analisar as relações entre os saberes de duas professoras, e a influência da trajetória socioprofissional na sua constituição e mobilização. Além desses exemplos, na análise empírica deste artigo após categorizar os saberes dos professores em um a das categorias unificados pudemos focar nos processos de 
formação e mobilização de saberes, isto é, no modo como cada docente vivencia seus conhecimentos. Assim, percebemos as diferentes influências da estrutura curricular (mais ou menos voltada para a formação docente), das vivências no curso de formação inicial (em relação ao desempenho acadêmico e participação em atividades extracurriculares) e da experiência profissional (de ensinar química e matemática; atuar como docente substituto ou efetivo) nesse processo.

Contribuímos para a área de pesquisa com uma proposta que reúne tipologias de análise acerca do conhecimento docente. Outros autores apontaram a diversidade que envolve a temática, a existência de similaridades entre os teóricos aqui discutidos e o uso de maneira paralela entre as categorias. Concordamos que não há uma disputa pelo termo na área, as tipologias dos autores não são vistas como opostas e usadas de forma paralela pelos pesquisadores. No entanto, defendemos o uso do termo unificação e entendemos que a falta de oposição e a ausência de divisão reforçam nossa busca pela unificação. Avançamos nessa discussão ao revelar similaridades entre as categorias apresentando uma tipologia unificadas que pode operacionalizar o processo de análise e evidenciar elementos formativos da docência. Apresentamos, teórica e empiricamente, uma proposta analítica de organizar e discutir os saberes docentes de modo unificado e consensual na área de pesquisa. Contudo, reforçamos que se trata apenas de uma tipologia e de categorizações que isoladas não permitem compreender a complexidade dos processos formativos e que não pode ser vista com uma perspectiva salvacionista. Reiteramos, então, a necessidade do acoplamento das tipologias a outras teorias de formação docente e humana que incorporem os saberes em uma análise mais ampla dos processos formativos.

Esperamos que a nossa proposta possa ser explorada por outros autores ou motivar novas sínteses teóricas, contribuindo para a sistematização das pesquisas acerca dos saberes dos professores e avançando na busca de mais consensos dentro da pesquisa em ensino de Ciências e de formação de professores. Entendemos que é necessário aprofundar as pesquisas para encontrar respostas para além da pergunta: quais saberes os professores mobilizam em suas aulas? Investigando também o quando, o como, o porquê e suas relações. Explorar a trajetória pessoal, escolar e profissional de professores é um caminho promissor para compreender sua formação e atuação docente. Defendemos pesquisas mais amplas que investiguem o professor de forma integral, considerando suas vivências, inclusive para além da sua prática em sala de aula. Assim identificaremos os saberes, utilizando uma tipologia unificada e consensual, e então entenderemos como se formam e como são mobilizados por docentes em sua prática pedagógica. 


\title{
For a unification of the typologies of teaching knowledge: searching for consensus in science teacher education
}

\begin{abstract}
The teacher knowledge theme is plural, complex and increasingly frequent in research on teacher education. A multiplicity of typologies, categories and classifications arise from wealth of information and researches on this subject. However, there are a lack attempts to systematize or seek similarities between different theoretical strands. The aim of this paper is argued about similarity between the theories of teacher knowledge and present, theoretically and empirically, a proposal of categorization. On the bases of Tardif, Gauthier, and Shulman we defend that: i) the terms are used as synonyms; ii) the definitions for the terms are similar, because they have rules of equivalence and iii) the typologies between the authors are different, but not excluding. We propose a unification of some categories, such as: content knowledge, pedagogical knowledge and curricular knowledge. For exemplification of the categorization proposal, we reported here an analysis with three chemistry teachers, based on individual interviews and investigation of their professional knowledge. The unification of typologies has the potential to highlight the relationships between the categories of teaching knowledge, operationalize the analysis process, highlight the formative elements of teaching and point out the urgency of deeper and less descriptive investigations of teachers' knowledge.
\end{abstract}

KEYWORDS: Teachers' knowledge. Unification of typologies. Tardif. Gauthier. Shulman. 


\section{AGRADECIMENTOS}

Agradecemos à Fundação de Amparo à Pesquisa do Estado de São Paulo (FAPESP) processo: 2015/23704-9, pelo financiamento da pesquisa.

\section{REFERÊNCIAS}

AGOSTINI, G.; MASSI, L. Desenvolvimento e mobilização de saberes docentes: influências da formação e da trajetória profissional em duas professoras de química. Enseñanza de Las Ciencias, v. extra, p. 2355-2359, 2017.

ALMEIDA, P. C. A.; BIAJONE, J. Saberes docentes e formação inicial de professores: implicações e desafios para as propostas de formação. Educação \& Pesquisa, v. 33, n. 2, p. 281-295, maio/ago. 2007.

ALVES, W. F. A formação de professores e as teorias do saber docente: contextos, dúvidas e desafios. Educação \& Pesquisa, v. 33, n. 2, p. 263-280, maio/ago. 2007.

BRAGA, L. As percepções dos licenciandos em química sobre a carreira do magistério: um estudo sobre o processo de aprendizagem docente. АCTIO, Curitiba, v. 3, n. 1, p.37-55, jan./abr. 2018.

BOGDAN, R.; BIKLEN, S. Investigação qualitativa em educação: uma introdução à teoria e aos métodos. Porto: Porto Editora, 1994.

BORGES, C. Saberes docentes: diferentes tipologias e classificações de um campo de pesquisa. Educação \& Sociedade, v. 22, n. 74, p. 59-76, abril. 2001.

BORGES, C.; TARDIF, M. Apresentação - Dossiê: Os saberes dos docentes e sua formação. Educação \& Sociedade, v. 74, Ano XXII, p. 11-26, abril. 2001.

BOZELLI, F. C. Saberes docentes mobilizados em contextos interativos discursivos de ensino de física envolvendo analogias. Tese de Doutorado em Educação para a Ciência - Faculdade de Ciências, UNESP, Bauru. 2010.

CONFORTIN, R.; CAIMI, F. Constituição e Mobilização de Saberes Docentes: Perscrutando Práticas de Professores de Biologia no Ensino Médio. Revista Brasileira De Pesquisa Em Educação Em Ciências, v. 17, n. 1, p. 157-181. 2017.

COSTA, F. R. S.; CAMARGO, S.; SILVA, C. S. A mobilização de saberes a partir do uso de diferentes materiais didáticos no contexto do PIBID. ACTIO, Curitiba, v.3, n. 1, p. 91-114, jan./abr. 2018.

CUNHA, E. R. Os saberes docentes ou saberes dos professores. Revista Cocar, v.1, n. 2, p. 31-39. 2007.

FEJOLO, T. B.; PASSOS, M. M.; ARRUDA, S. M. A socialização dos saberes docentes: a comunicação e a formação profissional no contexto do PIBID/física. Investigações em Ensino de Ciências, v. 22, n. 1, p. 103-126. 2017. 
FERNANDEZ, C. Revisitando a Base de Conhecimentos e o Conhecimento Pedagógico do Conteúdo de professores de Ciências. Ensaio - Pesquisa em Educação em Ciências, v. 17, n. 2, p. 500-528, maio-ago. 2015.

FINOQUETO, L. C. P. O professor inserido em instituições de atendimento sócioeducativo a adolescentes em conflito com a lei: a mobilização dos saberes docentes. Dissertação de mestrado em Educação. Universidade Federal de Santa Maria, Santa Maria. 2007.

FINOQUETO, L. C. P.; SANTOS, M. E. G.; TERRAZZAN, E. A. Dos saberes docentes ao desenvolvimento profissional dos professores. In 15을 Congresso Brasileiro de Leitura. Campinas, SP, 2005. Anais. Recuperado de: http://alb.com.br/arquivomorto/edicoes_anteriores/anais15/Sem13/leilafinoqueto.htm.

FIORENTINI, D.; SOUZA JÚNIOR, A. J.; MELO, G. F. A. Saberes docentes: um desafio para acadêmicos e práticos. In: C.M.G., Geraldi et al. (Org.), Cartografias do trabalho docente: professor (a) pesquisador (a) (pp. 307-335). Campinas: Mercado de Letras, 1998.

GAUTHIER, C.; MARTINEA, S.; DESBIENS, J.; MALO, A.; SIMARD, D. Por uma teoria da pedagogia: pesquisas contemporâneas sobre o saber docente. Editora Unijuí, 1998.

GOES, L. F. Conhecimento pedagógico do conteúdo: estado da arte no campo de educação e ensino de química. 2014. 155 f. Dissertação (mestrado) apresentado ao Instituto de Física, ao Instituto de Química, ao Instituto de Biociências e à Faculdade de Educação, Universidade de São Paulo, São Paulo, 2014.

LIMA, V. S. A.; KOCHHANN, M. E. R. Tecendo a constituição identitária do professor de matemática narrado nos memoriais. ACTIO, Curitiba, v. 3, n. 1, p. 184-204, jan./abr. 2018.

LONGHINI, M. D.; HARTWIG, D. R. A interação entre os conhecimentos de um professor atuante e de um aspirante como subsídio para a aprendizagem da docência. Ciência \& Educação, v. 13, n. 3, p. 435 - 451. 2007.

LUDKE, M. O professor, seu saber e sua pesquisa. Educação \& Pesquisa, ano XXII, n. 74. 2001.

MIZUKAMI, M. G. N. Aprendizagem da docência: algumas contribuições de L. S. Shulman. Revista Educação, v. 29, n. 2, p. 33-49, jul./dez. 2004.

MONTEIRO, A. M. F. C. Professores: entre saberes e práticas. Educação \& Sociedade, v. 22, n. 74, p. 121-142, abril. 2001.

MONTERO, L. A construção do conhecimento profissional docente. In: NÓVOA, António (Org.). Profissão professor. 2 ed. Porto: Porto Editora, 1995.

MUNBY, H.; RUSSELL, T.; MARTIN, A.K. Teachers' knowledge and how it develops. In: V., Richardson (Ed.). Handbook of research on teaching (p. 877-904). 
NETO, V. P. B.; COSTA, M. C. Saberes docentes: entre concepções e categorizações. Revista Tópicos Educacionais, v. 2, jul./dez. 2016.

NÓVOA, A. Os professores e as histórias da sua vida. In: A. NÓVOA (Org.). Vidas de professores. 2 ed. Porto: Porto Editora, 1995.

NUNES, C. M. F. Saberes docentes e formação de professores: um breve panorama da pesquisa brasileira. Educação \& Sociedade, ano XXII, v.74, p. 27-42, abril. 2001.

PUENTES, R. V.; AQUINO, O. F.; QUILLICI NETO, A. Profissionalização dos professores: conhecimentos, saberes e competências necessários à docência. Educar em revista, v. 34, p. 169-184, maio/ago. 2009.

RIBEIRO, M. T. D.; GONÇALVES, T. V. O. Os Saberes Docentes na Dinâmica pela Profissionalização do Trabalho Docente. Revista Thema, v. 15, n. 3, p. 991-1006, 2018.

ROLDÃO, M. C. Função docente: natureza e construção do conhecimento profissional. Revista Brasileira de Educação, 12(34), 94-103. 2007.

SHULMAN, L. Paradigms and research programs in the study of teaching: a contemporary perspective. In: M. C., WITTROCK (org.). Handbook of research on teaching (p. 3-36). 3 ed. Nova York: Macmillan. 1986a.

SHULMAN, L. Those who understand knowledge growth in teaching. Educational Researcher, v. 15, n. 2, p. 4-14. 1986b.

Shulman, L. Knowledge and teaching: foundations of the new reform. Harvard Educational Review, v. 57, n. 1, p. 1-21. 1987.

TARDIF, M. Saberes docentes e formação profissional. 17 ed. Petrópolis: Editora Vozes. 2014.

TARDIF, M.; LESSARD, C.; LAHAYE, L. Les enseignants des ordres d'enseignement primaire et secondaire face aux savoirs: Esquisse d'une problématique du savoir enseignant. Sociologie et sociétés, v. 23, n. 1, p. 55-69. 1991.

VIEIRA, M. M.; ARAÚJO, M. C. P. Os estudos de Shulman sobre formação e profissionalização docente nas produções acadêmicas brasileiras. Cadernos de Educação, 53. 2016.

ZANON, D. A. V.; OLIVEIRA, J. R. S.; QUEIROZ, S. L. O "saber" e o "saber fazer" necessários à atividade docente no ensino superior: visões de alunos de pósgraduação em química. Revista Ensaio, v. 11, n. 1, p. 140-159. 2009. 
Recebido: 10 mar. 2020

Aprovado: 10 jul. 2020

DOI: 10.3895/actio.v5n3.11746

Como citar:

AGOSTINI, G.; MASSI, L. Por uma unificação das tipologias de saberes docentes: em busca de consensos na formação de professores de ciências. ACTIO, Curitiba, v. 5, n. 3, p. 1-24, set./dez. 2020. Disponível em: <https://periodicos.utfpr.edu.br/actio>. Acesso em: XXX

Correspondência:

Gabriela Agostini

Av. Eng. Luís Edmundo Carrijo Coube, 14-01 - Núcleo Res. Pres. Geisel, Bauru, São Paulo, Brasil

Direito autoral: Este artigo está licenciado sob os termos da Licença Creative Commons-Atribuição 4.0

Internacional.

(c) (1) 